Jurnal Penelitian Pendidikan, Psikologi Dan Kesehatan (J-P3K) 2020, Vol. 1 (No. 2) : 75-81

\title{
Stres Kerja ditinjau dari Job Satisfaction pada Karyawan PT. SumatraSarana Sekar Sakti Medan
}

\section{Work Stress based Job Satisfcation on Employee at PT. SumatraSarana Sekar Sakti Medan}

\author{
Fredy $^{(1)^{*}}$, Ina Evita Sari Pasaribu ${ }^{(2)}$ \& Rianda Elvinawanty ${ }^{(3)}$ \\ Fakultas Psikologi, Universitas Prima Indonesia, Indonesia
}

Diterima : 14 Mei 2020; Disetujui : 19 Mei 2020; Dipublish : 29 Agustus 2020

*Corresponding author: E-mail: freech534@gmail.com

\begin{abstract}
Abstrak
Penelitian ini bertujuan untuk mengetahui hubungan antara job satisfaction dengan stres kerja. Subjek yang digunakan dalam penelitian ini adalah para karyawan PT. SumatraSarana Sekar Sakti Medan sebanyak 106 karyawan yang dipilih dengan metode teknik nonprobability yaitu sampel jenuh atau sering disebut total sampling. Data diperoleh dari skala untuk mengukur stres kerja dan job satisfaction. Analisis data yang digunakan adalah menggunakan korelasi Produck Moment melalui bantuan SPSS 20 for windows. Hasil data analisis data menunjukkan koefisien korelasi sebesar - 0.197 dengan p sebesar 0.021 ( $\mathrm{p}<0.05)$. Ini menunjukkan adanya hubungan negatif antara job satisfaction dengan stres kerja. Hasil penelitian ini menunjukkan bahwa sumbangan yang diberikan variabel job satisfaction terhadap stres kerja adalah sebesar $3.9 \%$ dan selebihnya 96.1\% dipengaruhi oleh faktor lain. Dari hasil penelitian ini dapat ditarik kesimpulan bahwa hipotesis penelitian ada hubungan negatif antara job satisfaction dengan stres kerja, dapat diterima.
\end{abstract}

Kata Kunci: Job Satisfaction; Karyawan; Stres Kerja.

\begin{abstract}
This study aims to determine the relationship between job satisfaction and work stress. The subjects of the study are 106 employee at PT. SumatraSarana Sekar Sakti Medan selected by the nonprobability technique method that is saturated sample or often called total sampling. Data were obtained from a scale for measuring work stress and job satisfaction. The analysis of the data was performed using product moment correlation with SPSS 20 for Windows. The result of data analysis showed that the correlation coefficient was -0.197 with $p 0.021(p<0.05)$. It showed that there is a negative correlation between job satisfaction and work stress. The result indicate that the contribution given to the variable of job satisfaction and work stress addiction is by $3.9 \%$ and the remaining $96.1 \%$ is affected by other factiors. From this result, it is concluded that the hypothesis stating there is a negative relationship between job satisfaction with work stress is accepted.
\end{abstract}

Keywords: Job Satisfcation; Employee; Work Stress.

Rekomendasi mensitasi :

Fredy, Pasaribu, I.E.S., \& Elvinawanty, R. (2020). Stres Kerja ditinjau dari Job Satisfaction pada Karyawan PT. SumatraSarana Sekar Sakti Medan. Jurnal Penelitian Pendidikan, Psikologi dan Kesehatan (J-P3K), 1(2): 75-81. 


\section{PENDAHULUAN}

Setiap organisasi yang didirikan yang bertujuan untuk berkembang, tetap hidup dan memenuhi fungsi sosialnya. Tujuan organisasi tersebut dipengaruhi oleh motivasi dan tekanan yang berasal dari dalam maupun luar perusahaan. Seiring dengan berkembangnya ilmu pengetahuan dewasa ini yang disadari dengan terciptanya mesin dan peralatan canggih, serta munculnya inovasi-inovasi kerja, sehingga perusahaan memerlukan karyawan yang memiliki ahli tertentu.

Organisasi merupakan wadah atau tempat kegiatan bagi orang yang bekerja sama dalam usahanya untuk mencapai tujuan. Tujuan tersebut pasti berbeda, misalnya dapat berupa laba, pelayanan sosial, peningkatan pendidikan, pembinaan karir, pujian dan sebagainya. Organisasi yang dimaksud adalah organisasi yang bertujuan untuk mendapatkan laba yang selanjutnya disebut sebagai perusahaan.

Perusahaan merupakan organisasi yang mempunyai peran besar dalam menopang pembangunan. Agar dapat berperan dalam pembangunan maka diperlukan suatu manajemen yang baik dan efektif, dan juga agar dapat mengelola faktor-faktor produksi sebaik mungkin, sehingga merupakan suatu kesatuan yang dapat digunakan untuk mencapai tujuan perusahaan. Untuk mencapai tujuan perusahaan tersebut tidak hanya ditentukan oleh besarnya dana yang dimiliki, teknologi yang digunakan, ataupun sarana dan prasarana yang ada dalam perusahaan tersebut, akan tetapi ada hal yang paling penting dalam proses penyatuan faktor-faktor yang dimiliki oleh perusahaan dalam proses pencapaian tujuannya yaitu Sumber Daya Manusia.

Sumber daya manusia (SDM) merupakan salah satu faktor yang terpenting dalam suatu perusahaan. Berhasil atau tidaknya perusahaan dalam mencapai tujuan, sangat dipengaruhi pada kemampuan SDM dalam menjalankan manajemen perusahaan dan tugas yang diberikan perusahaan. Karena SDM merupakan salah satu faktor yang sangat penting dalam suatu perusahaan di samping faktor lain seperti modal utama untuk menjalankan segala kegiatan operasional. Karena itu, perusahaan harus menciptakan suasana yang dapat mengembangkan prestasi kinerja dan motivasi pada setiap karyawan. Untuk meningkatkan produktivitas SDM dengan baik juga, mendaya gunakannya secara optimal. Pada akhirnya akan mencapai tujuan seperti yang diharapkan oleh manajemen perusahaan.

Sumber daya manusia merupakan aset terpenting perusahaan karena perannya sebagai subyek pelaksana kebijakan dan kegiatan operasional perusahaan. Ruang lingkup sumber daya manusia secara umum membahas hal yang berkaitan dengan manusiawi, salah satunya adalah job satisfaction. Job satisfaction merupakan faktor yang dianggap penting, karena dapat mempengaruhi para karyawan dalam perusahaan.

Dengan kemajuan teknologi pada jaman modern para karyawan dituntut untuk bisa mengoperasikan komputer, mulai dari hal dasar mengoperasikan komputer hingga akhirnya mampu mengambil kesimpulan dari data-data yang telah diolah menggunakan komputer. 
Bahkan keputusan seorang manager dalam mengambil keputusan terkadang sangat bergantung dari sistem informasi manajemen. Karyawan yang dituntut atau bahkan dipaksa untuk bisa menggunakan teknologi membuat seseorang tersebut akan merasa tertekan, karena dengan begitu banyak hal-hal yang harus dikuasai dan dipahami lagi untuk mengoperasikan teknologi tersebut. Waktu mereka akan tersita beberapa jam untuk mempelajari lagi hal tersebut. Dan biasanya perusahaan tidak memberikan pelatihan tentang ini. Hal ini dapat menyebabkan para karyawan sangat tertekan sehingga bisa menyebabkan stres dalam pekerjaan mereka.

Para karyawan menghadapi dengan keadaan seperti diatas, diperkirakan masalah tersebut dapat mengganggu kestabilan pikiran dan perilaku para karyawan. Seperti yang terjadi pada daerah Bekasi seorang karyawan yang bekerja di perusahaan PT Mitsuba Indonesia Pipe Part yang berada di kawasan Cibitung. Karyawan yang bernama Epi Suhendra sebagai pelaku yang terkait kasus pembunuhan terhadap istri dan anak kandungnya sendiri. Pelaku diduga melakukan pembunuhan dikarenakan stres karena tidak dapat memenuhi target dan menjadi beban bagi pelaku. Selain itu, peristiwa ini juga dilatarbelakangi karena himpitan ekonomi keluarga. Jabatan pelaku yang sebagai Leader takut diberhentikan, karena tidak mencapai target dalam tugasnya, sehingga pelaku merencanakan pembunuhan terhadap keluarga dan dirinya sendiri. (news.detik.com).

Ada juga masalah lain yang dihadapi oleh karyawan, salah satunya adalah karyawan atas nama Sarjono yang merupakan karyawan KONI (Komite Olahraga Nasional Indonesia). Beliau sudah bekerja selama 22 tahun sebagai karyawan KONI pusat. Karyawan tersebut mengatakan bahwa dia stres dan tidak berani ulang ke rumah yang dikarenakan karyawan tersebut belum mendapatkan gaji selama lima bulan. Sehingga istri dan anaknya sudah lima bulan hidup dari hutangan. Karyawan tersebut juga mengatakan bahwa dia baru pertama kali tidak digaji selama bulan. Beliau juga menginap di gedung KONI pusat. (www.tribunolahraga.com).

Sehubungan dengan kasus yang di paparkan di atas, berdasarkan wawancara terhadap beberapa karyawan PT. SumatraSarana Sekar Sakti. Beberapa karyawan mengaku bahwa pernah mengalami stres dalam pekerjaan mereka dan ada juga beberapa karyawan jarang mengalami kecemasan dalam pekerjaan. Para karyawan yang mengalami stres dalam pekerjaan mereka mengalami kendala yang sangat besar, sehingga kurangnya produktivitas pada karyawan tersebut. Beberapa karyawan yang mengalami stres ada yang mengatakan bahwa stres dikarenakan pekerjaan yang diberikan tidak sesuai dengan yang dikatakan, ada juga yang mengatakan stres dikarenakan penyampaian dari atasan yang tidak bisa disampaikan secara baik-baik. Dan beberapa karyawan yang mengatakan jarang cemas dalam pekerjaan, mereka mempunyai beberapa cara sendiri untuk tidak memikirkan masalah mereka yang bisa membuat mereka stres. Salah satu cara yang mereka lakukan adalah mendengarkan lagu. 
Berdasarkan paparan kasus dan hasil survei yang dilakukan peneliti dapat dilihat bahwa para karyawan masih banyak yang mengalami stres dikarenakan lingkungan pekerjaan, pekerjaan yang diberikan dan upah yang tidak diberikan. Hal ini membuat mereka menjadi stres terhadap pekerjaan mereka. Gejala-gejala inilah yang dialami karyawan yang dapat mengarah pada stres yaitu stres dalam bekerja.

Gibson (dalam Zainal, dkk, 2014) mengemukakan bahwa stres kerja dikonseptualisasi dari beberapa titik pandang, yaitu stres sebagai stimulus, stres sebagai respons dan stres sebagai stimulus-respon. Stres sebagai stimulus merupakan pendekatan yang menitikberatkan pada lingkungan. Definisi stimulus memandang stres sebagai suatu kekuatan yang menekan individu untuk memberikan tanggapan terhadap stresor. Pendekatan ini memandang stres sebagai konsekuensi dari interaksi antara stimulus lingkungan dengan respons individu. Pendekatan stimulus respons mendefinisikan stres sebagai konsekuensi dari interaksi antara stimulus lingkungan dengan respons individu. Stres dipandang tidak sekadar sebuah stimulus atau respons, melainkan stres merupakan hasil interaksi unik antara kondisi stimulus lingkungan dan kecenderungan individu untuk memberikan tanggapan.

Kemudian, Kahn dan Quin (dalam Wijono, 2012) mendefinisikan bahwa stres kerja merupakan faktor-faktor lingkungan kerja yang negatif seperti konflik peran, kekaburan peran, dan beban kerja yang berlebihan dalam pekerjaan. Selanjutnya, Rubin dan Mcneil (dalam Wijono, 2012) berpendapat bahwa rangsangan negatif dari lingkungan kerja dianggap sebagai penyebab stres eksternal dan tindakan secara emosional dan fisik sebagai penyebab stres internal.

Pada dasarnya pengaruh stres kerja ada yang menguntungkan maupun merugikan bagi perusahaan. Namun, pada taraf tertentu pengaruh yang menguntungkan perusahaan diharapkan akan memacu karyawan untuk dapat menyelesaikan pekerjaan dengan sebaikbaiknya. Reaksi terhadap stres dapat merupakan reaksi yang bersifat psikis maupun fisik. Biasanya pekerja atau keryawan yang stres akan menunjukkan perubahan perilaku. Perubahan perilaku terjadi pada diri manusia sebagai usaha mengatasi stres. Usaha mengatasi stres dapat berupa perilaku melawan stres (fight) atau freeze (berdiam diri).

Dampak negatif yang ditimbulkan stres dapat berupa gejala fisiologis, psikologis dan perilaku (Robbins, 2007). Dilihat dari gejala psikologis, stres dapat mengakibatkan ketidakpuasan, stres di tempat kerja dapat menimbulkan ketidakpuasan yang berkaitan dengan pekerjaan. Stres yang dialami oleh karyawan dapat merugikan perusahaan hal ini dapat dilihat dari banyaknya karyawan yang tidak masuk kerja dengan berbagai alasan, pekerjaan molor, dan kesalahan dalam perkerjaan.

$$
\text { Salah satu faktor yang }
$$
mempengaruhi stres kerja adalah job satisfaction. Berdasarkan penelitian yang dilakukan oleh Syah dan Indrawati (2016) terhadap sopir bus PO Agra Mas menunjukkan adanya hubungan negatif yang signifikan antara job satisfaction dengan stres kerja. Sopir bus yang memiliki kepuasan kerja yang rendah 
maka stres kerja akan tinggi, sebaliknya apabila sopir bus memiliki kepuasan kerja yang tinggi maka stres kerja akan rendah.

Locke (dalam Wijono, 2012), mendefinisikan job satisfaction sebagai suatu tingkat emosi yang positif dan menyenangkan individu. Dengan kata lain, job satisfaction adalah suatu hasil perkiraan individu terhadap pekerjaan atau pengalaman positif dan menyenangkan diirnya. Job satisfaction merupakan suatu tindakan efektif karyawan terhadap pekerjaannya. Job satisfaction tersebut dianggap sebagai hail pengalaman karyawan dalam kaitannya dengan penilaian terhadap diri sendiri seperti apa yang dikehendaki atau diharapkan dari pekerjaannya.

Hasibuan (dalam Hartatik, 2014), mengatakan bahwa job satisfaction adalah sikap emosional karyawan yang menyenangi dan mencintai pekerjaannya. Sikap ini dicerminkan oleh moral kerja, kedisiplinan, dan prestasi kerja. Job satisfaction dinikmati dalam pekerjaan, luar pekerjaan, dan kombinasi antara luar dan dalam pekerjaan. Fleisman dan Bass (dalam Wijono, 2012), menambahkan jika tingkat job satisfaction merupakan suatu sikap dan umpan balik karyawan terhadap pekerjaannya.

\section{METODE PENELITIAN}

Variabel yang digunakan dalam penelitian ini adalah variabel terikat dan variabel bebas. Variabel terikat adalah Stres Kerja dan Variabel Bebas adalah Job Satisfaction.

Stres kerja adalah suatu perasaan yang menekan atau rasa tertekan yang dialami karyawan dalam menghadapi pekerjaannya. Sedangkan Job satisfaction adalah sikap atau perasaan karyawan terhadap aspek-aspek yang menyenangkan atau tidak menyenangkan mengenai pekerjaan yang sesuai dengan penilaian masing-masing pekerja.

Adapun skala yang digunakan dalam penelitian ini adalah skala stres kerja dan job satisfaction. Skala stres kerja yang digunakan dalam penelitian ini disusun berdasarkan aspek-aspek stres kerja menurut Wijono (2012) ada 3 aspek, yaitu physiology, psychology, dan behavior. Dan skala job satisfaction yang digunakan dalam penelitian ini disusun berdasarkan aspek-aspek yang dikemukakan oleh Martoyo (Hartatik, 2014), ada tiga aspek dalam job satisfaction, yaitu work it self, supervisor, workers, promotion, dan pay.

Metode pengumpulan data yang digunakan dengan menggunakan metode pembagian skala untuk mengukur job satisfaction dengan stres kerja yaitu skala Likert. Pengujian reliabilitas pada skala stres kerja diperoleh sebesar 0.889 dan reliabilitas pada skala job satisfaction diperoleh sebesar 0.912 .

Populasi dalam penelitian ini adalah karyawan PT. SumatraSarana Sekar Sakti Medan sebanyak 106 orang dengan karakteristik subjek penelitian adalah berstatus karyawan tetap dan karyawan yang sudah bekerja minimal 1 tahun.

Metode pengambilan sampel yang digunakan dalam penelitian ini adalah teknik nonprobability yaitu sampel jenuh atau sering disebut total sampling. Sampel jenuh atau total sampling yaitu teknik pengambilan sampel dengan cara mengambil seluruh anggota populasi sebagai responden atau sampel (Sugiyono 2013). 
Teknik analisis yang digunakan untuk menganalisis data hasil penelitian ini adalah teknik korelasi Product Moment Pearson dengan menggunakan program SPSS 21 for windows.

\section{HASIL DAN PEMBAHASAN}

Deskripsi data berdasarkan kategori stres kerja dalam penelitian ini dengan total subjek penelitian 106 orang terdapat sebanyak 8 karyawan atau 7.5\% memiliki stres kerja yang rendah, terdapat 94 karyawan atau $88.7 \%$ yang memiliki stres kerja yang sedang dan terdapat 4 karyawan atau 3.8\% yang memiliki stres kerja yang tinggi. Dapat dikatakan bahwa rata-rata subjek penelitian memiliki perilaku stres kerja yang sedang.

Kategori job satisfaction dalam penelitian ini terdapat 2 karyawan atau 1.9\% memiliki job satisfaction yang rendah, terdapat 90 karyawan atau $84.9 \%$ memiliki job satisfaction yang sedang, dan terdapat 14 karyawan atau 13.2\% memiliki job satisfaction yang tinggi. Dapat disimpulkan bahwa rata-rata subjek penelitian memiliki job satisfaction sedang.

Dalam penelitian ini diperoleh juga mean empiric sebesar 72.21, dengan standar deviasi sebesar 9.167.

Tabel 1. Perbandingan Data Empirik dan Hipotetik Stres Kerja.

\begin{tabular}{|c|c|c|c|}
\hline \multicolumn{2}{|c|}{ Variabel Empirik } & \multirow{2}{*}{$\begin{array}{l}\text { Hipotetik } \\
30\end{array}$} & \multirow{2}{*}{$\frac{\text { Ket }}{\text { Min }}$} \\
\hline Stres & 51 & & \\
\hline Kerja & 98 & 120 & $\operatorname{Max}$ \\
\hline & 72.21 & 75 & Mean \\
\hline
\end{tabular}

Adapun uji hipotesis yang dilakukan dalam penelitian ini adalah adanya hubungan negatif antara job satisfaction dan stress kerja. Hasil analisis korelasi antara job satisfaction dan stres kerja, diperoleh koefisien korelasi product moment sebesar -0.197 dengan Sig.(p) sebesar 0.021 ( $\mathrm{p}<0.05)$. Hal ini menunjukkan bahwa adanya korelasi negatif antara job satisfaction dengan stres kerja.

\begin{tabular}{lll}
\multicolumn{3}{l}{ Tabel 2. Hasil Uji Korelasi } \\
\hline Analisis & $\begin{array}{l}\text { Pearson } \\
\text { Correlative }\end{array}$ & Signifikan (p) \\
& -0.197 & 0.021 \\
\hline Korelasi & -0.197 \\
\hline
\end{tabular}

Pada penelitian ini diperoleh koefisien determinasi $R$ Square $\left(R^{2}\right)$ sebesar 0.039. Berdasarkan hasil tersebut, dapat disimpulkan bahwa $3.9 \%$ job satisfaction mempengaruhi stres kerja. Adapun faktor yang turut mempengaruhi stres kerja diantaranya berupa shift kerja, dukungan sosial dan gaya kepemimpinan transformasional. Pada penelitian ini diperoleh kategorisasi data stres kerja dan job satisfaction dari karyawan di PT. SumatraSarana Sekar Sakti Medan yang menjadi subjek penelitian.

Berdasarkan uraian tersebut dapat dinyatakan bahwa ada hubungan antara job satisfaction dengan stres kerja. Semakin tinggi job satisfaction yang dirasakan karyawan, maka semakin rendah stres kerja, dan sebaliknya semakin rendah job satisfaction maka semakin tinggi stres kerja .

\section{SIMPULAN}

Berdasarkan uraian dan hasil analisis data di atas, peneliti menyimpulkan bahwa hipotesis yang diajukan oleh peneliti yaitu ada hubungan antara job satisfaction dengan stres kerja pada karyawan PT. SumatraSarana Sekar Sakti Medan. Dalam penelitian ini 
hipotesis tersebut dapat diterima. Pada penelitian ini juga diperoleh koefisien determinasi R Square $\left(\mathrm{R}^{2}\right)$ sebesar 0.039. Berdasarkan hasil tersebut dapat disimpulkan bahwa sumbangan 3.9\% job satisfaction mempengaruhi stress kerja.

\section{DAFTAR PUSTAKA}

Hartatik, P.I. 2014. Buku Praktis Mengembangkan SDM. Yogyakarta : Laksana.

Robbins, S. P. 2007. Perilaku Organisasi. Salemba Empat, Jakarta.

Sugiyono. 2013. Metode Penelitian Manajemen. Bandung: Penerbit Alfabeta

Syah, R. N., \& Indrawati, E. S. 2016. Hubungan Antara Kepuasan Kerja dengan Stres Kerja Pada Sopir Bus PO Agra Mas. Jurnal Empati Vol.5, No.3, 543-548.

Wijono, S. 2012. Psikologi Industri dan Organisasi : Dalam suatu Bidang Gerak Psikologi Sumber Daya Manusia. Jakarta : Kencana.

Zainal, V. R., Hadad, M. D., \& Ramly, M., 2014. Kepemimpinan dan Perilaku Organisasi. Jakarta: Rajawali.

Mei, 2014, Kronologi Sadisnya Epi Suhendar Bunuh Anak Kandung, detik.com [diakses $\left.\begin{array}{lllll}\text { pada } & 30 & \text { juli } & 2019 & 21.35\end{array}\right]$ https://news.detik.com/berita/2479421/kro nologi-sadisnya-epi-suhendar-bunuh-anakkandung.

Olii, S., 2019, Sarjono, Karyawan KONI Stres Berat Tak Berani Pulang ke Rumah, tribunolahraga.com [ diakses pada 30 juli 2019 http://www.tribunolahraga.com/2019/05/16 /olimpiade/sarjono-karyawan-koni-stressberat-tak-berani-pulang-ke-rumah. 